\title{
新工科背景下应用化学专业工程创新能力培养体系的建设
}

吴祥, 朱成峰, 付延明, 李芳, 李冰, 李有桂

合肥工业大学化学与化工学院, 合肥 230009

摘要: 在新工科背景下, 合肥工业大学应用化学专业通过调整专业培养目标、课程体系、教学内容、教学模式以及 师资队伍建设等方面的探索实践, 实现了应用化学专业工程创新能力的增强, 满足了当今社会对应用化学专业人才 的需求。该实践对以新工科理念改造升级传统专业具有一定的指导意义。

关键词: 新工科; 应用化学; 工程创新; 实践教学

中图分类号: G64; O6

\section{Construction of Engineering Innovation Ability Training System for Applied Chemistry Specialty under the Background of Emerging Engineering Education}

\author{
Xiang Wu, Chengfeng Zhu, Yanming Fu, Fang Li, Bing Li, Yougui Li * \\ School of Chemistry and Chemical Engineering, Hefei University of Technology, Hefei 230009, China.
}

\begin{abstract}
Under the background of emerging engineering education, the applied chemistry major of Hefei University of Technology has realized the enhancement of the engineering innovation ability of the applied chemistry major and met the society's demand for applied chemistry professionals through the adjustment of professional training objectives, curriculum system, teaching content, teaching mode, and construction of the teaching staff. The practice provides guidance for the transformation and upgrading of traditional majors with the concept of emerging engineering education.
\end{abstract}

Key Words: Emerging engineering education; Applied chemistry; Engineering innovation; Practical teaching

2017年2月以来, 教育部积极推进 “新工科” 建设, 先后形成了 “复旦共识” “天大行动” 和 “北京指南”, 并发布了《关于开展新工科研究与实践的通知》 《关于推荐新工科研究与实践项目 的通知》, 全力探索形成领跑全球工程教育的中国模式、中国经验, 助力高等教育强国建设 ${ }^{[1]}$ 。

“新工科”建设的提出是我国教育界为响应国家提出的实施创新驱动发展战略以及 “中国制造 2025 ” “互联网+” “一带一路” 等一系列政策举措对工程人才的新需求而在工程教育领域开展的 新改革 ${ }^{[2]}$ 。面向 “新工科” 建设的工程人才的关键能力, 应包含专业精神、专业能力、可持续发展能 力等三个方面, 应具有普适性与联通性特征。

应用化学是化学和化学工程与工艺之间的桥梁, 是把化学理论转变为大规模化工过程之间的过 渡研究过程, 是新型产品开发的基础。应用化学专业所具备的特征与 “新工科” 理念高度一致。在

收稿: 2021-07-26; 录用: 2021-08-05; 网络发表: 2021-09-07

“通讯作者, Email: liyg@hfut.edu.cn

基金资助: 合肥工业大学课程思政教改示范课程项目(kcsz2019024) 
“新工科” 背景下, 根据应用化学专业自身特点, 如何更好地发挥应用化学专业在人才培养中的作 用是一个重要课题。按照 “新工科” 理念对应用化学专业进行改造, 突出应用能力、强化专业特色、 加强工程实践能力培养、完善协同育人体系建设等, 使应用化学专业人才培养能够更好地适应新技 术、新产业、新业态的发展和行业产业发展的需要 ${ }^{[3,4]}$ 。本文主要介绍合肥工业大学应用化学专业在 新工科背景下, 通过调整专业培养目标、课程体系、教学内容、教学模式及师资队伍建设等方面, 加强应用化学专业工程创新能力的培养, 满足当今社会对应用化学人才需求方面所做的探索。

\section{1 依托学科优势, 优化培养方案}

合肥工业大学应用化学学科发展较早, 硕士研究生招生始于1984年, 是合肥工业大学最早的硕 士学位授予点之一; 应用化学学科在1996年被评为机械部重点学科, 2000年被评为安徽省重点学科。 经过 18 年的发展, 于 2002 年开始招收应用化学专业本科生。专业起点高、师资力量强, 专业课程设 置及内容与科研方向结合紧密。应用化学专业在化学、材料科学 (二者皆为全球ESI排名前 $1 \%$ )和化学 工程与技术(学科评估为 $\mathrm{B}+$ )等一级学科支撑下, 彰显扎实的理科基础和较强的工科实力。

2015年, 学校提出了以能力为导向的 “培养目标-教学过程-质量提升” 三位一体的教学体系, 对所有专业的培养计划进行了调整和完善。经过4年的实践, 在新工科的理念指导下, 2019年又对 2015版的专业培养计划进行了修订。应用化学专业培养目标是培养具有良好的科学知识、文化素养 和高度的社会责任感, 掌握化学、化工专业基础理论和专业知识与技能, 能够从事化学、化工领域 的科学研究、技术开发及生产应用等方面工作的德才兼备、能力卓越、自觉服务国家的专业技术人 才以及具有开阔的国际视野、较强的创新意识和实践能力的复合型人才。毕业要求共有十点, 其中 体现工程能力方面的有: (1) 具有运用数学、自然科学、工程基础和专业知识, 分析和探讨化学、化 工、材料领域的技术与工程实际问题, 并得到合理有效结论的能力。(2) 具有综合运用化学、化工、 材料的基本原理及现代科研工具, 对专业领域的理论和技术问题进行研究, 包括文献分析、实验设 计、数据获取与分析, 并初步解决目标问题的能力。(3) 具有开展精细化工相关领域的研发与设计、 分析与检测、技术改造与创新的初步能力。(4) 理解并掌握化学、化工、材料领域的安全环保知识、 行业标准与政策, 具有良好的质量、安全、效益、环境、职业健康和可持续发展意识。

\section{2 师资队伍的建设}

为保证学科发展, 培养符合企业和行业需要的具有高素质工程创新能力的专业人才, 教师的工 程背景是重要的支撑和保障、是满足专业教学的需要。本专业现有教师 25 名, 全部具有博士学位, 其中教授 10 人, 副教授 9 人, 讲师 6 人, 具有海外学习经历的教师有 19 人, 是一支年龄结构、职称结 构、学缘结构合理的高素质师资队伍。

为加强师资队伍工程实践能力的培养, 本专业坚持 “引进来” 和 “走出去” 的原则, 加强 “双 师” 型师资队伍的建设。“引进来” 包括两个方面, 一是引进具有工程经验的教师。目前教师队伍 中有 5 人具有在企业中工作 2 年以上的工作经历, 具有丰富的工程化实践能力; 二是聘请企业有经验 的工程师作为学生的企业导师。“引进来” 有效提高了学生工程实践能力的培养效果, 也促进了校 企合作、产教融合。“走出去” 则能解决当前大部分教师 “从高校到高校” 导致的工程实践经验缺 失问题。学院鼓励、引导和规范教师特别是青年教师或到企业兼职、或以博士后身份在企业从事技 术产品研发工作, 或以横向课题合作方式参与企业的技术改造和科技攻关, 从而强化专业教师的工 程经验和实践能力, 目前已有 12 名教师到企业锻炼半年以上。同时, 在已有师资队伍的基础上, 进 一步加强教师的工程实践能力的系统培训, 让教师结合自身专业知识, 了解行业管理、工程实践技 能、获取相关行业实践信息与资源，培养教师进一步提高自己的工程背景和工程实践能力。

此外, 以企业委托项目为抓手, 以工程化课题为导向, 以科研训练、大学生创新创业计划以及 本科毕业论文为主要渠道, 吸纳本科生参与研究, 使学生充分了解学科前沿和行业发展, 培养学生 
运用所学知识解决实际问题的科学素养和工程创新能力。在指导学生以及解决具体工程问题的过程 中, 教师队伍的工程实践能力随之得到增强, 从而进一步反哺专业教学, 实现教学相长, 达到良性 循环。

\section{3 以工程能力培养为引领, 构建科学的理论课程体系}

按照学校统一要求, 专业课程包括通识教育课程、公共基础课程、专业必修课程、专业选修课 程、实践课程、创新创业课程。按照教学规律和知识学习的难易进行课程设置, 本专业与工程能力 培养关系密切的课程见表 1 。

表 1 工程能力培养课程设置一览表

\begin{tabular}{cll}
\hline \multicolumn{1}{c}{ 时间 } & \multicolumn{1}{c}{ 理论课程(学分) } \\
\hline 大一上学期 & 高等数学(6)、工程 \\
大一下学期 & 高等数学 (3)、大学物理(5) MATLAB程序设计(2) & MATLAB程序设计(1) \\
大二上学期 & 大学物理、线性代数(2.5) & 工程训练(1)、科研训练(I) (1) \\
大二下学期 & 电工与电子技术(3) & 大学物理实验(1) \\
大三上学期 & 化工原理(4.5)、精细有机合成工艺学(2) & 电工与电子技术实验 (1)、认知实习(1)、科研训练(II) (1) \\
大三下学期 & 化工制图与CAD (2) & 化工原理实验(1)、化工实习实训(I) (1) \\
大四上学期 & 化工环保(2)、化工仪表与自动化(2)、化工设备机械基础(2) & 化工实习实训(II) (1)、专业设计实验(2)、毕业实习(2) \\
大四下学期 & & 毕业设计(论文) (18) \\
\hline
\end{tabular}

从表 1 中可见: 理论课程总学分为 36 , 其中必修课学分为 28 ; 除毕业设计(论文)外的实践课程的 总学分为 15 。工程能力培养课程体系十年不间断, 学分比例较高, 强化了工程能力的培养。

\section{4 实践教学体系的构建}

应用化学专业的特点是 “理工结合”，与应用理科及 “新工科” 的理念高度契合。本专业既注 重了理论知识也加强了工程能力的培养。本专业积极探索实践教学改革, 形成了特色鲜明的 “从理 论到实践、从实验到工程、从综合到创新” 的 “四年不断线、循序渐进的三层次”一体化实践教学 体系。实践教学中融入了新工科的理念, 增加综合性、设计性、研究性实验, 加强课程设计、毕业 设计与生产、工程实际结合的力度, 突出工程教育理念, 强化学生工程创新能力培养。具体实施措 施如下。

\section{1 工程创新能力的培养}

工程创新能力的培养分为三个层次。第一层次主要通过课程实验和初步的综合(或设计)实验, 验证和深化理解课程讲授的重要基本理论, 掌握实验操作技能以及严谨、规范的实验习惯; 通过创 新教育, 培育创新意识, 同时建立专业与工程的概念。第二层次通过学科基础课程综合实验、设计 实验、科研训练等, 培养学生的组织能力、综合运用知识能力、初步的创新和工程能力。第三层次 主要以毕业设计(论文)和创新实践为主, 加强高年级学生创新与工程能力的培养, 使毕业生获得从 事本学科领域科学研究与工程设计的初步能力。

在第一层次的通识教育下, 本专业主要强化综合运用能力和工程创新能力两个层次的培养。为 实现第二层次培养目标, 具体措施如下: (1) 实验内容进行革新。在电化学方向, 紧跟学科前沿, 开 设 “ $\mathrm{CuInS}_{2}$ 修饰ITO导电玻璃电极的制备及二氧化碳的光电催化还原” 实验; 结合最新行业发展, 开 设了 “锂离子电池的制作与性能测试” 实验; 围绕产品需求, 开设了涂层防护的 “电化学腐蚀实 验” 。在有机合成方向, 围绕有机合成新技术, 开设 “微波法合成乙酰水杨酸” 实验; 围绕精细化 工工业, 开设 “食品防腐剂山梨酸钾的制备” 实验; 紧跟实际应用, 开展 “抗癫㾋药一一苯妥英 
钠的合成” 多步综合实验。(2) 实行科研训练导师制。每名学生从大一开始, 配备一名科研训练导 师。在导师的指导下, 学生大一阶段对某一特定课题进行文献综述; 大二阶段则对此课题提出新的 研究方案, 形成完整的科研训练报告, 以此检验科研训练的效果。(3) 开展专业设计实验。以 $2-4$ 人 的小组为单位进行专业设计实验, 根据导师提供的实验题目或自选的实验题目, 自行查阅文献资料, 自行设计实验方案, 自选和组装实验装备, 自拟实验操作步骤, 在规定的时间内完成实验。学生做 完实验后，对实验结果进行分析和总结并提交完整的专业设计实验报告。

为实现第三层次培养目标, 具体措施如下: (1) 以大学生创新创业训练计划为依托来提高工程 能力。在导师指导下, 本科生个人或团队, 自主完成创新性研究项目设计、研究条件准备和项目实 施、研究报告撰写、成果(学术)交流等工作。或在导师指导下, 创业训练项目团队中每个学生在项目 实施过程中扮演一个或多个具体的角色, 通过编制商业计划书、开展可行性研究、模拟企业运行、 参加企业实践、撰写创业报告等工作。(2) 通过参加 “挑战杯” “互联网+” “创青春” 等创新创业 大赛来检验创新实践成果。鼓励具备较强科研能力且有一定科研成果的同学, 在教师指导下参加各 种创新创业大赛, 以赛促学、以赛促研、以赛促练, 同时以赛促教, 实现整体工程创新水平的提高。 (3) 在校外实践基地开展毕业实习。学生在毕业实习过程中, 下车间、进工位, 了解每道工序的操作 流程、了解整条生产线的运作过程、了解背后的化学化工知识和设计逻辑, 将理论与实际相结合, 从而促进工程能力的提高。(4) 毕业论文是培养学生各项能力的一个重要环节, 也是学生培养效果 的集中展现。通过开题报告、中期检查、最终答辩和毕业论文, 实现对学生的系统训练; 指导教师 通过审核开题报告、写作记录卡、中期检查、论文初稿、学术不端行为检测以及论文最终版, 提交 指导记录等过程管理, 来提高毕业论文质量。

\section{2 校内工程实践平台}

应用化学专业校内工程训练分成两个部分, 一是在校工培中心进行的工程训练, 二是在化工实 训基地开展的化工实习实训。

合肥工业大学工业培训中心是国家级实验教学示范中心, 本专业学生的工程训练由该中心承担。 通过示范、示教、设计、实训和综合创新制作, 学生自己动手完成基础工程技术和现代制造技术等 一系列的工程训练项目, 模拟准工厂生产环境, 获得对现代工业生产方式和生产工艺过程的基本认 识, 接受生产工艺技术组织管理能力的基本训练; 并通过初级、中级、高级等多层次教学训练手段, 形成较完整的工程培训平台, 培养学生的工程意识、创新思维, 训练与提高学生的工程素质和技术 实践能力。

合肥工业大学化学与化工学院在国内高校中率先建设了综合程度高、小型化、准工厂规模的校 内 “化工实训基地” 。基地分一期实训基地和二期实训基地, 一期实训基地是对学生进行化工基本 技能的训练, 培养学生动手能力, 使其掌握有关化工设备的设计、安装、操作及性能测试以及在工 程实际中的应用等方面的基本技能和知识。一期实训基地有不同材质的 4 套 $100 \mathrm{~L}$ 反应釜生产设备及 产品性能分析测试仪器, 4套配备管道切割、管螺纹加工等设备的流体输送管路拆装系统, 以及锅炉、 真空、压缩、冷冻等公用工程设备。二期实训基地是工程实践创新基地, 主要有无机反应-分离系统、 有机反应-分离系统、气体吸收-解吸净化系统、多相催化反应评价系统、中压功能材料合成与改性系 统等 5 套实训装置。通过在工程装置上的实际动手操作, 较好地弥补了实习过程中学生 “只能看、不 能动” 的不足, 培养学生初步的化工系统工程、产品工程、控制工程和安全环保等方面的工程知识 和理念, 提升学生设计能力、动手能力、分析和解决问题等工程实践能力和创新能力。

\section{3 校外实践基地与产学研项目的发展}

联合安徽广信农化股份、东华工程科技、中盐安徽红四方、安徽安利新材料、安徽省化工设计 院等单位成立设计课程组、实习课程组和青年教师培训组等, 构建了产业全程融入、校企协同育人 的新模式。例如安徽广信农化股份有限公司的实践基地的运行模式, 首先签订平台合作协议, 明确 双方的责任和义务、确定双方的负责人; 然后制定培养方案, 采取双导师制即每个学生都要明确学 
校和企业的导师, 三方共同协商确认项目内容是否能达到工程实践能力培养目标要求; 最后通过考 核来确认联合培养效果。

产学研紧密结合促进专业建设发展。本专业利用在学科建设、基地建设和人才培养等方面所取 得的优势, 加强与省内外大型、特大型医药、化工等企业间的联系与合作。目前, 专业合作的大型 企业有 40 余家, 如中盐红四方、安庆石化、铜陵有色、海螺集团、中航集团、丰乐农化、安徽蚌埠 丰原集团、新宇药业等。通过校企产学研合作，有效解决困扰企业发展的技术难题的同时，也有力 促进了专业的建设, 真正体现 “互利共赢”。

通过产学研合作, 明确了专业教师的科研方向, 提升了教师的工程教育能力和服务社会的能力。 近年来, 专业教师与企业合作, 成功申报包括国家科技支撑计划、省部级重大科技攻关等在内的各 类产学研项目 60 多项, 累计项目经费达 8000 多万元。

\section{5 建设成效}

通过一系列举措, 人才培养质量持续提升, 成果丰硕。近三年来, 本科生 13 人次发表 SCI论文 8 篇; 18 人次申报国家发明专利; 8 人次参加全国大学生化工设计竞赛并获奖, 11 人次参加全国大学 生化工实验竞赛并获奖; 毕业生就业率均为 $100 \%$, 其中 2020 年的升学率为 $48.7 \%$, 进入 “985” “双 一流” 高校的学生比例超过 $90 \%$; 有 2 名同学在毕业之前创办了与专业相关的企业。同时, 教师教研 水平也得到了大幅度的提高, 先后获得省级教学成果奖特等奖、一等奖各 1 项; 主持完成省部级质量 工程项目、教研项目 8 项, 省级教学名师 4 人、省级教坛新秀 2 名。教师研究成果转化 5 项。

\section{6 结语}

高等教育坚持 “立德树人, 以本为本” 这一核心目标, 围绕此目标, 以 “新工科、应用理科” 理念为指导, 根据当今社会经济发展的需求, 结合当今教育教学新技术、新理念, 应不断调整和完 善专业培养目标、课程体系、教育教学方式方法, 加强师资队伍建设, 探索新形势下应用化学专业 人才工程能力培养新模式, 把工程教育先进经验融入到应用化学专业人才培养中, 探索出应用化学 专业人才培养新模式。

\section{参 考 文 献}

[1] 胡波, 冯辉, 韩伟力, 徐雷. 复旦教育论坛, 2017, 15 (2), 20.

[2] 钟登华. 建设“新工科”培养卓越工程人才. 中国教育报, 2017-06-07.

[3] 张树永, 朱亚先. 中国大学教学, 2018, No. 3, 25.

[4] 张树永, 朱亚先, 霍冀川, 宋丽娟, 徐华龙, 郑兰荪. 大学化学, 2020, 35 (10), 6. 